\title{
NOVAS PERSPECTIVAS NO ESTADIAMENTO E TRATAMENTO DO CÂNCER DE ESÔFAGO
}

\author{
New perspectives in esophageal cancer staging and treatment \\ Leonardo Gomes da FONSECA, André Beer FURLAN, Juliana Ferreira FERRANTI, \\ Guilherme Naccache NAMOUR, Frederico Lafraia LOBO, Sérgio SZACHNOWICZ, \\ Rubens Antônio Aissar SALLUM, Ivan CECCONELLO
}

ABCDDV/573

Fonseca LG, Furlan AB, Ferranti JF, Namour GN, Lobo FL, Szachnowicz S, Sallum RAA, Cecconello I. Novas perspectivas no estadiamento e tratamento do câncer de esôfago. ABCD Arq Bras Cir Dig 2007;20(4):274-9

RESUMO - Introdução - O câncer de esôfago apresenta-se como uma das neoplasias mais freqüentes e letais. O acometimento linfático aparece como principal fator individual de pior prognóstico, sendo a esofagectomia com linfadenectomia extensa ainda seu tratamento de escolha. Ressecções mais extensas através da toracotomia estão associadas com maior sobrevida, mas apresentam altas taxas de morbimortalidade. O conceito de micrometástases pode nos trazer avaliação mais acurada do estadiamento dos tumores operados, com detecção através de imunoistoquímica ou reação em cadeia de polimerase de metástases não diagnosticadas pelos métodos convencionais. Métodos - Realizou-se revisão bibliográfica de artigos científicos publicados e disponíveis no PubMed, através do site www.pubmed.gov. cruzando-se os descritores neoplasias esofágicas, biologia molecular, estadiamento de neoplasias, linfonodo sentinela, metástase linfática. Revisão da literatura - O conceito do linfonodo sentinela, onde se pesquisa durante a cirurgia os possíveis primeiros sítios de metástases, direcionando desta maneira a rota da ressecção linfática no intuito de permitir ressecções completas não necessariamente extensas, possibilita diminuir a morbimortalidade e restringir as indicações de procedimentos muitas vezes super-dimensionados que podem não trazer benefício aos pacientes. Conclusão - O estadiamento preciso através da procura de micrometástase e o tratamento mais regrado pelo método do linfonodo sentinela, podem trazer novas perspectivas no tratamento do câncer de esôfago, principalmente em casos de tumores precoces.

DESCRITORES - Neoplasias esofágicas. Biologia molecular. Estadiamento de neoplasias. Linfonodo sentinela. Metástase linfática (EXISTEM ?)

\section{INTRODUÇÃO}

O câncer de esôfago apresenta-se como uma das neoplasias mais freqüentes e letais. Nas últimas décadas sua incidência vem aumentando consideravelmente com altas taxas de mortalidade em vários países. A doença predomina em faixas etárias avançadas, com maior ocorrência entre a sexta e sétima década de vida, e no sexo masculino, com razão de 4:1 em relação ao minino ${ }^{11}$.

Sua incidência varia geograficamente. É alta sobretudo em países como a China, Japão, Turquia, Cingapura e Porto Rico, onde alguns locais apresentam taxas maiores que 130/100000 habitantes. No ocidente, a incidência é de aproximadamente 5 a 10 em 100000 habitantes. Nos Estados Unidos, estimam-se 14520 novos casos e 13570 mortes por câncer de esôfago em 2005 e aumento em sua incidência de $10 \%$ ao ano ${ }^{11}$. No Brasil, este tipo de câncer está entre os 10 mais incidentes, sendo considerado o sexto tipo mais letal no ano de 2000, com 5307 óbitos. As estimativas para 2006 são de 10580 novos casos da doença no país ${ }^{19}$.

O câncer de esôfago apresenta dois tipos histológicos

Trabalho realizado no Departamento de Gastroenterologia da Faculdade de Medicina da Universidade de São Paulo - Disciplina de Cirurgia do Aparelho Digestivo e de Coloproctologia, São Paulo, SP, Brasil

Endereço pra correspondência: Ivan Cecconello, e-mail: icecconello@terra.com.br mais comuns: o mais freqüente é o carcinoma epidermóide (CEC), seguido pelo adenocarcinoma.

A taxa de sobrevida geral após cinco anos é de aproximadamente $10 \%$ nas populações ocidentais, em contraste com a de $4 \%$ observada na década de $1970^{11}$. Apesar desta melhora na sobrevida, seu prognóstico continua insatisfatório e seu tratamento merece novos estudos na busca de melhores resultados.

A classificação TNM é utilizada para determinar o grau de disseminação da doença e auxiliar na estimativa do prognóstico, levando em consideração principalmente o número de linfonodos acometidos. Kunisaki et al. ${ }^{15}$, através de 113 esofagectomias, compararam 5 métodos de estadiamento diferentes, observando que os que consideravam o número de linfonodos acometidos ao invés dos padrões de distribuição anatômica das metástases linfonodais, obtiveram melhor relação entre estadiamento e prognóstico. A presença de metástases linfonodais é vista, em muitos estudos, como um fator prognóstico independente. Estes estudos ressaltam a grande importância da realização de estadiamento linfonodal o mais acurado possível.

Os métodos atualmente utilizados para ele no pré-operatório são o ultrassom endoscópico, tomografia computadorizada helicoidal e a tomografia com emissão de pósitrons. Ainda assim, estes métodos apresentam baixa 
especificidade na avaliação de gânglios acometidos, não sendo incomum o estadiamento pré-operatório ser alterado após a ressecção do esôfago com linfadenectomia extensa, onde gânglios suspeitos não se confirmam invadidos, e mais freqüentemente, gânglios comprometidos são ressecados sem terem sido suspeitos previamente.

O tratamento de escolha para o câncer de esôfago é a esofagectomia radical com linfadenectomia ${ }^{16}$, e depende de estadiamento eficaz da doença e da investigação de metástases linfonodais e sistêmicas.

Lerut et al. ${ }^{17}$ mostraram sobrevida de cinco anos em $90 \%$ de pacientes em estádio I, 56\% em pacientes de estádio II e $15 \%$ e $0 \%$ nos estádios III e IV, respectivamente, o que vem a confirmar a possibilidade de cura em tumores não-avançados submetidos a tratamento cirúrgico.

A ressecção do esôfago deve ser acompanhada da linfadenectomia extensa interessando as regiões de drenagem linfática do órgão, ou seja, cervical e abdominal além da região torácica que pode ser acessada através de acesso transdiafragmático sem toracotomia, ou pelo acesso torácico direto através de toracotomia direita ou toracoscopia.

Hulscher et al. ${ }^{8}$ observaram menor morbidade no procedimento transhiatal quando comparado à via transtorácica com linfadenectomia. No entanto, esta última esteve relacionada a discreta melhoria na sobrevida em cinco anos possivelmente por realizar linfadenectomia mais completa ${ }^{6}$ , confirmada por vários autores, principalmente nos casos em que a recorrência cervical e metástases mediastinais eram mais prováveis.

Ainda não existe consenso na literatura quanto ao acesso com melhor custo-benefício para o tratamento do câncer de esôfago. Linfadenectomia extensa (3 campos) apesar de trazer maior chance de sobrevida, vem associada com maior morbimortalidade. A maior parte destes pacientes apresenta co-morbidades clínicas cardiovasculares e respiratórias além do alto índice de desnutrição. Neste contexto, o conceito de micrometástases pode nos trazer avaliação mais acurada do estádio dos doentes operados, assim como o linfonodo sentinela sinalisa novas perspectivas quanto às modalidades terapêuticas, restringindo ressecções muitas vezes super-dimensionadas que podem não vir acompanhadas de benefício aos pacientes.

\section{Micrometástases}

O conceito de micrometástases foi introduzido há cerca de 20 anos, com a detecção de células tumorais malignas em medula óssea e em sangue periférico de pacientes com câncer de mama. Estudos recentes definem micrometástases como a presença de uma única célula, ou grupo de até cinco células detectáveis por métodos imunoistoquímicos em linfonodos e médula óssea. Grupos maiores do que cinco células já podem ser reconhecidos por exame histológico convencional e por isso são chamados de metástases ${ }^{4}$.

Mueller et al. ${ }^{21}$ observaram que mesmo após esofagectomia radical curativa, era freqüente a recorrência da doença, mostrando a ineficiência do estadiamento realizado. Outros estudos notaram recidiva do tumor em $30 \%$ a $45 \%$ de pacientes classificados como N0 após operação teoricamente curativa ${ }^{22}$. Estes dados sugerem a insuficiência dos métodos atuais de estadiamento em mostrar correta correlação com o prognóstico do paciente. A progressão da doença eventualmente se mostra diferente mesmo em pacientes com o mesmo estádio.

As micrometástases vêm sendo estudadas como um fator prognóstico relevante em diversos tipos de câncer. Braun et al. ${ }^{1}$, em estudo multicêntrico envolvendo cerca de 5000 pacientes com câncer de mama, encontrou relação entre a presença de micrometástases em medula óssea e pior prognóstico. Nos com câncer gástrico, Ishida et al. ${ }^{7}$ também encontraram pior prognóstico em pacientes com micrometástases. A relação delas com o prognóstico em câncer de esôfago vem sendo discutida em diversos estudos, mas os resultados ainda mostram-se bastante conflitantes.

A detecção de micrometástase é realizada por métodos imunoistoquímicos ou moleculares baseados na reação em cadeia de polimerase (PCR).

A imunoistoquímica é técnica que usa anticorpos para ligar antígenos celulares específicos do tecido em estudo a marcadores como corante fluorescente, enzimas, elemento radioativo, que são de melhor visualização ao microscópio. Este processo pode ser realizado de forma direta, onde o anticorpo marcado se liga diretamente ao antígeno celular procurado, ou indireta, em que um anticorpo não-marcado se liga ao antígeno celular e anticorpos marcados se ligam ao anticorpo não-marcado, amplificando o sinal.

A grande maioria dos estudos que usam a imunoistoquímica para identificação das micrometástases em câncer de esôfago utiliza o coquetel AE1/AE3 $\left(\right.$ Dako $^{\circledR}$ ) de anticorpos anti-citoqueratina. Esta preparação de anticorpos monoclonais de rato é especifica para citoqueratinas humanas e as reconhece em células epiteliais, que na ausência de metástases não se encontram na medula óssea e nos linfonodos. Desta forma, a detecção de células epiteliais nas aspirações de medula óssea e nos linfonodos ressecados caracteriza a micrometástase.

A técnica do PCR, desenvolvido por Kary B. Mullis em $1985^{14}$, consiste na detecção de determinada seqüência de DNA através da replicação desta em milhões de cópias. A evolução desta técnica resultou no PCR em tempo real, método mais recentemente utilizado na localização das micrometástases pelas vantagens de precisão e detecção da amplificação do PCR nas fases mais precoces da reação, conferindo rapidez, pois permite análise do produto antes do final do processo.

A detecção das micrometástases do câncer de esôfago em medula óssea e linfonodos por PCR em tempo real visa identificar características na expressão do material genético das células neoplásicas que são diferentes das células normais. Assim, se houver micrometástases no processo de deteç̧ão, ocorre a extração do RNA mensageiro (RNAm) que codifica proteínas como o antígeno cárcino-embrionário (CEA), presentes apenas nas células tumorais. A partir deste RNAm é sintetizado o DNA complementar (DNAc) que será amplificado e indicará a presença de células neoplásicas no tecido estudado. 
Quanto à presença de micrometástases linfonodais no câncer do esôfago a literatura diverge sobre sua real correlação com a sobrevida. Alguns autores ressaltam esta correlação em estudos iniciais. De acordo com Izbicki et al. ${ }^{10}$, existem evidências de que células tumorais isoladas, ou aglomerados de células tumorais, detectadas por imunoistoquímica, é fator prognóstico independente em câncer esofágico. No seu estudo, todos os pacientes que não possuíam envolvimento tumoral linfonodal em análise histológica e imunoistoquímica sobreviveram o período médio de observação de 21 meses sem recorrência, enquanto que os sem metástase linfonodal convencional (por antomopatológico), porém com micrometástases em linfonodos, tiveram prognóstico semelhante aos pacientes com metástase linfonodal convencional. Natsugoe et al. ${ }^{14}$ mostraram que pacientes com carcinoma espinocelular do esôfago sem metástases linfonodais ( $\mathrm{pN} 0$ ) onde foram identificadas micrometástases, têm o mesmo prognóstico reservado como os casos de $\mathrm{pN} 1$. Assim, a reclassificação de pacientes $\mathrm{pN} 0$ com micrometástases para pN1 é justificada. Ainda, Komukai et al. ${ }^{23}$ demonstraram recorrência significantemente maior em pacientes com micrometástases do que naqueles sem elas, assim como a curva de sobrevida geral foi pior nos pacientes com acometimento micrometastático. Nesse estudo, micrometástase linfonodal foi o único fator de risco independente de recorrência pósoperatória de câncer de esôfago em pacientes com metástase linfonodal convencional.

Por outro lado, há autores que não encontraram impacto prognóstico das micrometástases em câncer de esôfago. Glickman et al. ${ }^{5}$ concluiu que a presença de micrometástase linfonodal não constitui indicador independente de mau prognóstico, tanto em pacientes com adenocarcinoma com carcinoma espinocelular, inclusive não sendo recomendada realização de linfadenectomias mais extensas nos pacientes com citoqueratina positiva em linfonodos sem metástases histológicas. Nakamura et al. ${ }^{22}$, mostraram que micrometástase linfonodal não foi fator prognóstico útil, em estudo com 53 pacientes com carcinoma espinocelular $\mathrm{pN} 0$ os quais foram submetidos à esofagectomia curativa. Porém, os com micrometástases obtiveram risco maior de metástase linfonodal. Tanabe et al. ${ }^{27}$, ao estudar 78 pacientes que foram submetidos à esofagectomia, concluiu que as micrometástases linfonodais não são evento raro no carcinoma espinocelular de esôfago. No entanto, aparentemente não possui significância clínica, somente se correlacionado com formas de câncer multicêntrico intraesofágico e invasão venosa.

Há poucos estudos de micrometástases em medula óssea em câncer de esôfago. Não há método padronizado, portanto é difícil esclarecer a importância clínica de seus achados. As taxas de detecção de micrometástase variam de 15 a $38,7 \%$, na medula óssea da crista ilíaca. Thorban et al..$^{28}$, em análise multivariada, mostrou importância prognóstica significativa na detecção de micrometástase de medula óssea em pacientes com carcinoma espinocelular de esôfago. Foi evidenciado mau prognóstico de pacientes citoqueratina-positiva em comparação a citoqueratina-negativos com diminuição significativa no tempo de sobrevida geral. Nakamura et al. ${ }^{22}$ também evidenciaram sobrevida de pacientes com micrometástases de medula óssea significativamente menor do que pacientes sem. Ademais, foi demonstrado que recorrência hematogênica foi mais freqüente em pacientes com micrometástase de medula óssea do que aqueles sem.

\section{Linfonodo sentinela}

Em 1892, Herbert Snow ${ }^{25}$ mostrou a importância do acometimento linfonodal nas doenças malignas e desde então a linfadenectomia em pacientes com linfonodos clinicamente suspeitos e patologicamente comprometidos por metástases é consenso para o tratamento destas doenças.

Porém, a linfadenectomia extensa em pacientes com suspeita de metástases linfonodais por vezes encontra linfonodos não comprometidos prejudicando o paciente pelo tratamento realizado ser mais extenso que o necessário.

O conceito de linfonodo sentinela (LS) surgiu em 1977 com Cabanas ${ }^{3}$, quando sugeriu, após o estudo anatômico de 100 pacientes, que o carcinoma de pênis normalmente metastatiza para o linfonodo localizado imediatamente superior a junção safenofemural. Desta forma, se o LS estivesse comprometido, o paciente necessitaria de linfadenectomia, caso negativo seria desnecessária. Com esta suposição, um linfonodo específico estaria relacionado a drenagem tumoral e o primeiro a receber invasão, e nenhuma célula neoplásica poderia "pular" esse primeiro linfonodo. Esse seriao local em que o primeiro estágio de metástase ocorreria. Conseqüentemente, se o linfonodo não estiver comprometido, teoricamente não seria necessário estender-se a linfadenectomia.

Recentemente estudos demonstraram que tumores sólidos normalmente metastatizam para determinada região linfática que pode variar entre os pacientes. Assim a localização anatômica tem menor importância que a identificação da drenagem linfática específica do paciente, ou seja, a localização do LS específico para cada tumor e individualizado por paciente ${ }^{25}$.

Em 1992, Morton et al. ${ }^{20}$ demonstrou como identificar as áreas de drenagem primária de melanomas por meio da linfocintilografia, utilizando-se de dextrose marcada com tecnécio. Obteve alta acurácia em melanomas iniciais com metástases linfonodais, indicando a linfadenectomia radical.

A técnica utilizada na obtenção do LS é essencial para o sucesso do mapeamento linfático intra-operatório. Caso o procedimento ocorra de maneira incorreta, resultados falso-negativos e subseqüente erro no tratamento ocorrerão. Desta maneira cada membro da equipe, desde o cirurgião até o patologista, tem papel importante e crítico no resultado final do mapeamento linfático.

Em 2000 Kitagawa et al. ${ }^{12}$ apresentou a técnica de injeção de 0,15-0,4 mCi de solução coloidal com tecnécio-99m no volume de 1 a $2 \mathrm{~mL}$ na submucosa de quatro pontos de 188 lesões primárias, das quais 33 eram câncer de esôfago. Com isso de 2 a 16 horas depois, durante a operação, um probe portátil de raios-Gama era utilizado para localizar os linfonodos com 10 vezes mais radioatividade 
que o restante do tecido adjacente, sendo considerados como LS. Concluíram que o intervalo de duas horas é suficiente para localização dos LS pelo Gama-probe. Estudaram ainda, com sucesso, a detecção laparoscópica do LS em câncer gastrointestinal.

A introdução do colóide radioativo melhorou a técnica do mapeamento no câncer do trato gastrointestinal e permitiu o mapeamento esofágico. Parungo et al. ${ }^{24}$ em 2005 utilizando imagens fluorescentes com ondas próximas ao infra-vermelho em três grupos de porcos Yorkshire, mostrou eficiência na detecção de LS no intra-operatório de esofagectomias.

A drenagem linfática do é mais complexa que a da pele e da mama, onde a validade do conceito de LS já foi definida. Estudos realizados pelas equipes lideradas por Siewert e Maruyama no final dos anos noventa demonstraram que no trato gastrointestinal o linfonodo que recebe a metástase inicial não necessariamente é aquele adjacente a tumores no estômago, por exemplo, os linfonodos perigástricos, com possibilidade de ser um linfonodo de cadeia secundária ou terciária.

Esse conceito foi denominado de "skip metastasis", ou seja, metástase saltadora, pois teoricamente ela não atingiu o primeiro nível linfonodal esperado, mas sim os subseqüentes. Outros autores questionam o conceito de "skip metastasis" e levantam a possibilidade de que o LS não é necessariamente aquele localizado o mais próximo do tumor, mas sim que ele pode ser variável de pessoa para pessoa ou de acordo com o comportamento biológico de cada tumor. Outra peculiaridade do LS no trato gastrointestinal é a freqüente presença de mais de um linfonodo como primeiro sítio provável de metástase linfática. São encontrados de dois a quatro linfonodos no câncer de cólon e gástrico e de quatro a seis no câncer de esôfago ${ }^{13}$. Isso ocorre pois a drenagem do trato gastrointestinal é multidirecional, o que implica em grande complexidade de seu sistema linfático.

O mesmo padrão errático e imprevisível do comportamento das metástases linfonodais pode ser visto em estudo do padrão de disseminação do CEC de esôfago em pacientes com um único linfonodo acometido. Oitenta e dois por cento dos pacientes com CEC intra-torácico apresentavam uma metástase abdominal ou na transição cérvico-torácica. Grande parte do conhecimento do comportamento das metástases linfonodais do CEC de esôfago foram obtidos através de estudos retrospectivos em pacientes com doença em estádios iniciais ou naqueles com metástase linfonodal única ${ }^{9,18}$.

O sistema de drenagem linfática do esôfago é único, com complexa rede de vasos linfáticos que se estendem longitudinalmente ao longo de todo órgão conectando com as regiões cervical, torácica e do estômago. Já a camada muscular do órgão drena diretamente para linfonodos intratorácicos peri-esofágicos. Quase $10 \%$ dos pacientes com doença restrita a mucosa (T1a) já apresentam metástases linfonodais. Quando o tumor invade a submucosa (T1b) a prevalência de pacientes com linfonodos acometidos atinge até $50 \%$. Logo, pode-se dizer que esse é um evento precoce na história natural da doença ${ }^{26}$. Em tumores intra-torácicos menos avançados, T1 e T2, o primeiro sítio de metástases, em cerca de $80 \%$ dos pacientes, são linfonodos perigástricos ou da transição tóraco-cervical, como os linfonodos dos nervos laríngeo-recorrentes. Já tumores extra-murais, T3 e T4 tendem a emitir metástases mais diretamente aos linfonodos intra-torácicos. Portanto pacientes com doença em estádios iniciais tendem a apresentar metástases à distância, quando na verdade tais linfonodos estão próximos de seu sistema de drenagem linfática, sugerindo doença localizada. Dado que corrobora essa teoria é o de que a sobrevida encontrada para pacientes com um único linfonodo acometido perigástrico ou na transição toraco-abdominal foi de $65 \%{ }^{18}$.

Em 2004 Burian et al. ${ }^{2}$ afirmou que apesar de ainda ser realizada em caráter experimental, o mapeamento do LS mostra-se executável e confiável nos estágios iniciais do adenocarcinoma do esôfago distal. No entanto, as diferenças entre os pacientes, a etiologia, a fisiopatologia, a topografia e o comportamento biológico, entre o adenocarcinoma e o CEC, faz com que seja necessária análise independente dessas duas variantes histológicas.

Assim como em outros órgãos do trato gastrointestinal em que a técnica do LS foi utilizada, foram encontrados múltiplos linfonodos em um único paciente com médias variando entre dois e quatro. Muitas vezes tais linfonodos localizavam-se em direções opostas, tanto acima quanto abaixo dos tumores.

Os índices de detecção de LS nesses primeiros estudos são semelhantes aos iniciais com o melanoma ou câncer de mama. A grande maioria dos autores conseguiu identificar ao menos um linfonodo em $90 \%$ dos pacientes durante a exploração intra-operatória com o probe. As falhas na detecção geralmente ocorrem em pacientes com doença localmente avançada (T3 e T4), devido a problemas técnicos na injeção do Tc99m (vazamentos), ou o uso de partículas radioativas muito grandes, que teriam maior dificuldade em atingir os linfonodos.

Lamb et al. ${ }^{16}$ observaram que os diferentes padrões de drenagem linfática apresentados por tumores no esôfago pode levar à altas taxas de falsos-negativos com a técnica do LS.

É importante ressaltar que pacientes incluídos em protocolos de rádio e quimioterapia passam a ser contraindicados para o emprego da técnica do LS, pois essas terapêuticas podem alterar o padrão de drenagem linfática do local afetado.

Portanto a utilização do LS no esôfago ainda não está totalmente estabelecida, pois existem muitos fatores ainda não resolvidos. Porém, mostra-se de grande interesse, uma vez que a drenagem linfática do esôfago é muito extensa e impõe operações muito invasivas e com alta morbimortalidade no intuito de se realizar a linfadenectomia adequada. $\mathrm{O}$ conceito de LS poderia minimizá-la permitindo melhorar em muito e evolução do tratamento cirúrgico do câncer de esôfago.

\section{Considerações finais}

As micrometástases vêm ganhando destaque nos estudos que abordam os mecanismos de progressão do câncer. 
Recentemente, graças ao desenvolvimento de metodologias eficazes, já é possível identificar células provenientes do tumor primário em sítios como a medula óssea e linfonodos antes mesmo do estabelecimento de metástases à distância. Embora em alguns tipos de câncer, como no de mama e no de estômago, o valor prognóstico das micrometástases já é observado em diversos estudos, no câncer de esôfago os resultados ainda são controversos.

Izbick et al. ${ }^{10}$ observaram a relação entre micrometástases e pior prognóstico, demonstrando que pacientes com micrometástases linfonodais apresentavam sobrevida semelhante aqueles com metástases linfonodais convencionais. Da mesma forma, Komukai et al. ${ }^{14}$, encontraram maior índice de recorrência em pacientes com câncer de esôfago e micrometástases em linfonodos, além de menor sobrevida, em comparação a pacientes sem doença micrometastática. Por outro lado, Glickman et al. e Nakamura et al. ${ }^{5,10,22}$, não encontraram relação entre micrometástases e prognóstico no câncer de esôfago. Um importante ponto de discussão no estudo das micrometástases é a metodologia de detecção. A técnica de PCR apresenta sensibilidade de detecção de uma célula tumoral em 107 normais, enquanto que a imunoistoquímica tem sensibilidade de deteç̧ão de uma célula tumoral em 106 normais. No entanto, a especificidade da PCR é comprometida pela eventual detecção de expressão dos genes de interesse em células que não as tumorais, impossibilitando a distinção entre falsos-positivos e verdadeiros-positivos. Natsugoe et al. ${ }^{23}$, ao compararem ambos os métodos, encontraram maior freqüência de micrometástases pela técnica de PCR, utilizando a mesma amostra. Isso indica a diferença de sensibilidade e especificidade dos métodos.

Outro ponto importante é a localização das micrometástases. As células tumorais podem se disseminar pelas vias hematogênica, linfática ou invasão local. Os dois sítios mais freqüentes para as micrometástases são a medula óssea e os linfonodos. O primeiro ocorre por disseminação hematogênica e o segundo por via linfática. Ainda não está definido qual desses dois sítios pode representar melhor a malignidade do câncer. Izbicki et al. ${ }^{10}$ sugeriram que as micrometástses linfonodais apresentam maior valor prognóstico do que as micrometástases em medula óssea.

A associação da presença de micrometástases com maior recorrência da doença ou pior sobrevida é contro- versa considerando: diferentes métodos de detecção da micrometástase; viés de seleção dos pacientes; pacientes com diferentes padrões histológicos de câncer e diferentes métodos de análise de dados.

Os estudos com LS em pacientes com CEC de esôfago limitam-se à análise desses linfonodos com o exame por coloração de hematoxilina-eosina e imunoistoquímica. Nenhum estudo avaliou o uso de PCR. Apenas com exame anatomopatológico convencional, a sensibilidade do LS para prever o status linfonodal do paciente varia entre $86 \%$ e $93 \%$. No estudo em que se utilizou imunoistoquímica para análise dos linfonodos, a técnica foi capaz de predizer o status linfonodal em todos os pacientes com ao menos um LS identificado. Em metade dos pacientes considerados N0 ao exame anatomopatológico convencional, a imunoistoquímica permitiu identificar micrometástases no LS, o que melhorou a acurácia do estadiamento em $33 \%$.

Da mesma forma que o estadiamento, o tratamento cirúrgico do câncer de esôfago pode ganhar força com estas duas técnicas somadas. O estadiamento mais acurado melhora a seleção dos pacientes com indicação de operação radical, além da realização de possível linfadenectomia seletiva, direcionada pelo LS bem identificado pelas técnicas de pesquisa de micrometástases, poderia melhorar os resultados do tratamento cirúrgico, minimizando sua morbimortalidade.

Contudo a utilização do LS no CEC de esôfago constitui um desafio. Poucos trabalhos com metodologia adequada foram publicados. A injeção de compostos radioativos derivados do Tecnécio99 no dia anterior à operação por endoscopia é método mais promissor. Aparentemente a sua utilização deve ganhar força em futuro próximo, porém seguindo as restrições aos tumores precoces já observadas em outros carcinomas do trato gastrointestinal.

\section{CONCLUSÃO}

Existem perspectivas reais que a detecção de micrometástases associada ao conceito do LS durante o ato operatório possa em futuro próximo trazer mudanças no estadiamento e por conseguinte na conduta cirúrgica, re-estadiando o doente, dirigindo a linfadenectomia para forma seletiva e impedindo que procedimentos muito extensos sejam realizados em pacientes com prognóstico já reservado. 
Fonseca LG, Furlan AB, Ferranti JF, Namour GN, Lobo FL, Szachnowicz S, Sallum RAA, Cecconello I. New perspectives in esophageal cancer staging and treatment. ABCD Arq Bras Cir Dig 2007;20(4):274-9

ABSTRACT - Background - The esophageal cancer presents as one of the most frequent and lethal neoplasia. Lymphatic involvement appears to be the principal individual factor for poor prognosis, thus esophagectomy with extensive lymphadenectomy still is the choice treatment. Thoracotomy for extensive resection is related to higher survival rate, as well as higher morbid-mortality rates. Micrometastasis concept involves a more accurate staging method for resected tumors, using immunohistochemistry or polymerase chain reaction techniques, which were not diagnosed by conventional methods. Methods - A literature review was made over scientific articles published and available at PubMed site (www.pubmed. gov), crossing the following headings: esophageal neoplasm, molecular biology, neoplasm staging, sentinel lymph node, lymphatic metastasis. . Literature review - Sentinel lymph node concept consist of intraoperative identification of possible primary dissemination metastasis sites, thus guiding to a more complete and not so extensively lymphatic resection, decreasing morbid-mortality and restraining an over-dimensioned procedure that may not benefit the patient. Conclusion - Accurate staging by micrometastasis identification and precise treatment using sentinel lymph node method may bring new perspectives in the esophageal cancer treatment, especially on early-stages tumors.

HEADINGS - Esophageal neoplasm. Molecular biology, Neoplasm staging, Sentinel lymphnode. Lymphatic metastasis.

\section{REFERÊNCIAS}

1. Braun S, Florian, D, Vogl FD, Naume B, Janni W, Osborne MP, et al. A Pooled Analysis of Bone Marrow Micrometastasis in Breast Cancer. New England Journal of Medicine. 2005; 358(8),793-802

2. Burian M, Stein HJ, Sendler A, et al. Sentinel lymph node mapping in gastric and esophageal carcinomas. Chirurg. 2004;75(8):756-60

3. Cabanas RM. An approach for the treatment of penile carcinoma. Cancer. 1977,39:456

4. Coons A.H., Creech H. J.Jones R.N. Immunological properties of an antibody containing a fluorescent group. Proc. Soc. Exp. Biol. Med. 47:200

5. Glickman JN, Torres C, Wang HH, Turner JR, Shahsafaei A, Richards WG. The prognostic significance of lymph node micrometastasis in patients with esophageal carcinoma. Cancer. 1999;85(4): 768-778.

6. Hulscher JB, Van Sandick JW, De Boer AG, Wijhoven BP, Tijssen JG, Fockens $\mathrm{P}$, et al. Extended transthoracic resection compared with limited transhiatal resection for adenocarcinoma of the esophagus. The New England Journal of Medicine. 2002; 347(21): 1662-1669.

7. Igaki H, Tachimori Y, Kato H. Improved survival for patients with upper and/or middle mediastinal lymph node metastasis of squamous cell carcinoma of the lower thoracic esophagus treated with 3-field dissection. Ann Surg. 2004;239(4):483-90

8. Ishida K \& Mori S. Extensive lymph node dissection for thoracic esophageal carcinoma. Japanese Journal Of Cancer.1989;16(4):1044-1050.

9. Isono K, Sato H, Nakayama K. Results of a nationwide study on the three fields of lymph node dissection in esophageal cancer. Oncology. 1991;48(5):411420 .

10. Izbick JR, Hosch SB, Pichlmeier U, Rehders A, Busch C, NiendorfA. Prognostic value of immunohistochemically identifiable tumor cells in lymph nodes of patients with completely resected esophageal cancer. The New England Journal of Medicine. 1997; 337(17):1188-1194.

11. Jemal A, Siegel R, Ward E, Murray T, Xu J, Smigal C, et al.Cancer statistics, 2006.CA Cancer Journal for Clinicians. 2006; 56(2):106-130.

12. Kitagawa Y, Fujii H, Sasako M, et al. The role of the sentinel lymph node in gastrointestinal cancer. Surg Clin North Am. 2000;80:1799-809.

13. Kitagawa $Y$, Kubota T, Ando N, et al. Sentinel node navigation for esophageal, gastric and colorectal cancer. Proceedings of American Society of Clinical Oncology; 200: 2280.

14. Komukai S, Nishimaki T, Watanabe H, Ajioka Y, Suzuki T, Hatakeyama K. Significance of immunohistochemically demonstrated micrometastases to lymph nodes in esophageal cancer with histologically negative nodes. Surgery. 2000;127(1):40-46.
15. Kunisaki C, Akiyama H., Nomura M, et al. Developing an Appropriate Staging System for Esophageal Carcinoma. J Am Coll Surg. 2005;201:884-90

16. Lamb PJ, Griffin SM, Burt AD, et al. Sentinel node biopsy to evaluate the metastatic dissemination of oesophageal Adenocarcinoma. British Journal of Surgery. 2005;92:60-7

17. Lerut T, De Leyn, Coosemans W, Van Raemdonck D, Scheys I, LeSaffre E. Surgical Strategies in Esophageal Carcinoma With Emphasis on Radical Lymphadenectomy. Annals of Surgery. 1992, 216(5): 583-590.

18. Matsubara T, Ueda M, Kaisaki S. localization of initial node metastasis from carcinoma of the thoracic esophagus. Cancer; 2000: 89(9): 1869-1873.

19. Ministério da Saúde. Secretaria de Assistência à Saúde. Instituto Nacional de Câncer - INCA. Estimativas da Incidência e Mortalidade por Câncer. Rio de Janeiro: INCA, 2006.

20. Morton DL, Wen DR, Wong JH, et al. Technical detaisls of intraoperative lymphatic mapping for early stage melanoma. Arch Surg. 1992;127:392-9

21. Mueller JD, Stein HJ, Oyang T, Natsugoe S, Feith M, Werner M, et al. Frequency and Clinical Impact of Lymph Node Micrometastases and Tumor Cell Microinvolvement in Patients with Adenocarcinoma of the Esophagogastric Junction. Cancer. 2000; 89(9): 1874-1882

22. Nakamura T, Hiroko I, Reiki E, Kazihiko H, Ota M, Takahashi K. Clinical implications of Lymph node Micrometastasis in Patients with Histologically Node-Negative (pN0) Esophageal carcinoma. Journal of Surgical Oncology. 2002; 79(4): 224-229.

23. Natsugoe S, Matsumoto M. Okumura H, Nakashima S, Higashi H, Uenosono $\mathrm{S}$, et al. Initial Metastatic, including micrometastatic, sites of lymph nodes in esophageal squamous cell carcinoma. Journal of Surgical Oncology. 2005; 89(1):6-11

24. Parungo CP, Ohnishi S, Kim SW, et al. Intraoperative identification of esophageal sentinel lymph nodes with near-infrared fluorescence imaging. J Thorac Cardiovasc Surg. 2005;129:844-50

25. Snow H. Melanotic cancerous disease. Lancet. 1872;2:872

26. Stein HJ, Feith M, Bruecher BL, et al. Early Esophageal Cancer Pattern of Lymphatic Spread and Prognostic Factors for Long-Term Survival After Surgical Resection. Ann Surg. 2005;242:566-75

27. Tanabe T, Nishimaki T, Watanabe H, Akioka Y, Akazawa K, Komukai K, et al. Immunohistochemically detected micrometastasis in lymph nodes from superficial esophageal squamous cell carcinoma. Journal of Surgical Oncology. 2003; 82(3):153-159.

28. Thorban S, Rosemberg A, Busch R, Roder RJ. Epithelial cells in bone marrow of oesophageal cancer patients: a significant prognostic factor in multivariate analysis. Britsh Journal of Cancer. 2000; 83(1) :35-39.

Conflito de interesse: não há

Fonte financiadora: não há

Recebido para publicação em: 22/07/2007 Aceito para publicação em: 13/10/2007 